SUPPORTING INFORMATION

\title{
In situ X-ray Diffraction and Spectro-Microscopic Study of ALD Protected Copper Films
}

Gül Dogan, ${ }^{1,2, *}$ Umut T. Sanli, ${ }^{2}$ Kersten Hahn, ${ }^{3}$ Lutz Müller, ${ }^{1}$ Herbert Gruhn, ${ }^{4}$ Christian Silber, ${ }^{1}$ Gisela Schütz, ${ }^{2}$ Corinne Grévent, $1,{ }^{*}$ and Kahraman Keskinbora ${ }^{2 *}$

${ }^{1}$ Robert Bosch GmbH, Automotive Electronics, Postfach 13 42, 72703 Reutlingen, Germany

${ }^{2}$ Max Planck Institute for Intelligent Systems, Heisenbergstr 3, 70569 Stuttgart, Germany

${ }^{3}$ Max Planck Institute for Solid State Research, Heisenbergstr 1, 70569 Stuttgart, Germany

${ }^{4}$ Robert Bosch GmbH, Corporate Sector Research and Advance Engineering, Robert-BoschCampus1, 71272 Stuttgart, Germany

*Corresponding Authors:

guel.dogan@de.bosch.com, corinne.grevent@de.bosch.com and keskinbora@is.mpg.de 

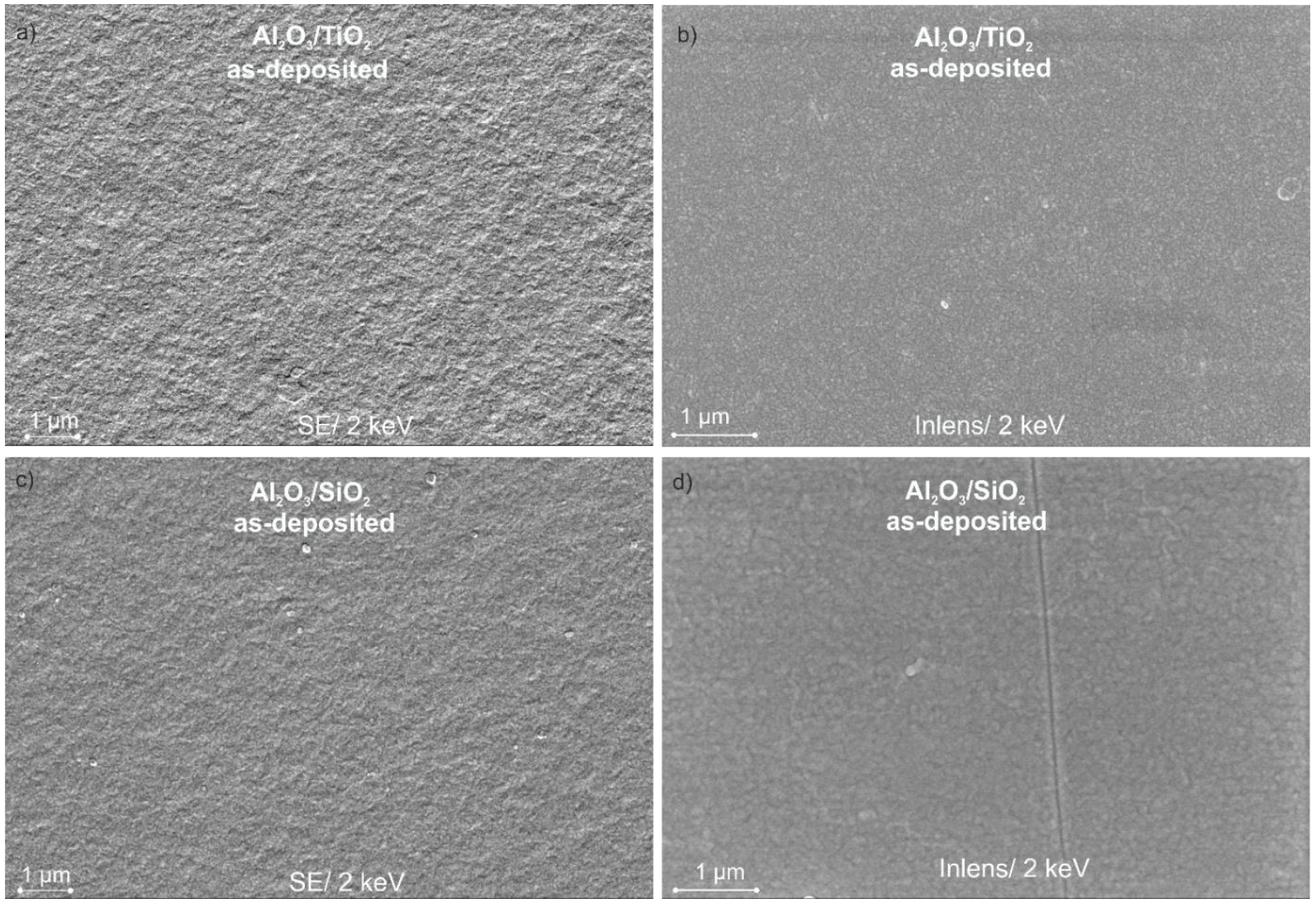

Figure S1. Surface properties of a-b) $\mathrm{Al}_{2} \mathrm{O}_{3} / \mathrm{TiO}_{2}$ and $\left.c-d\right) \mathrm{Al}_{2} \mathrm{O}_{3} / \mathrm{SiO}_{2}$ bilayers before annealing. The SEM images were taken in $2 \mathrm{keV}$ with SE (a,c) and Inlens (b,d) detector respectively. The similar morphology observed on the surface for both layers that contributed amorphous ALD layers continued copper' surface properties. Additionally, no void structure is observed on both bilayers. 

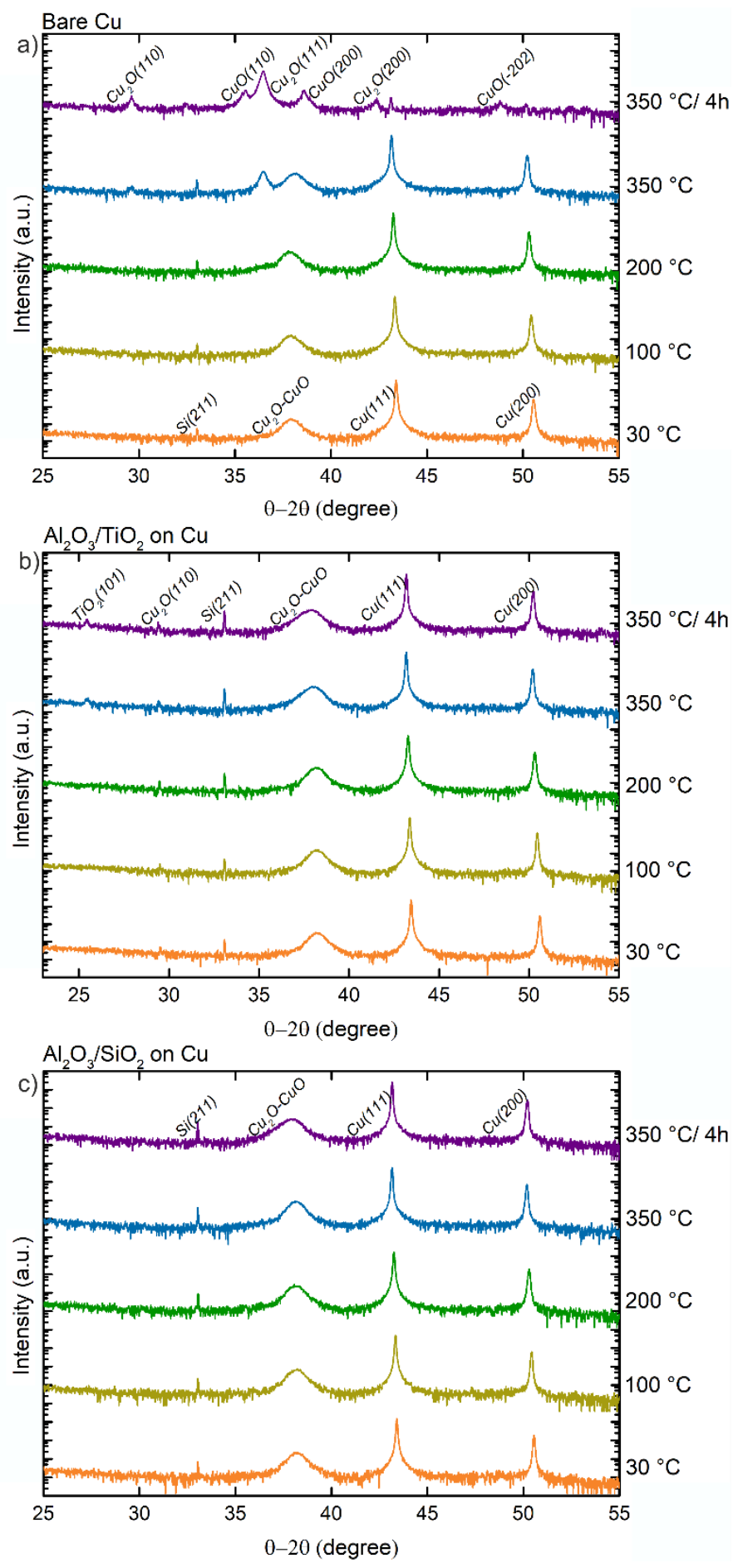

Figure S2. Diffraction data of set-point control measurements at $30{ }^{\circ} \mathrm{C}, 100{ }^{\circ} \mathrm{C}$ and $200{ }^{\circ} \mathrm{C}$ with additional of annealing at $350{ }^{\circ} \mathrm{C}$. a) Bare copper oxidation started at $350{ }^{\circ} \mathrm{C}$ with two main oxide peak separation at $2 \theta=37.5^{\circ}$ b) $\mathrm{Al}_{2} \mathrm{O}_{3} / \mathrm{TiO}_{2}$ bilayer showed that amorphous $\mathrm{TiO}_{2}$ phase transformed to anatase phase at $350{ }^{\circ} \mathrm{C}$. c) $\mathrm{Al}_{2} \mathrm{O}_{3} / \mathrm{SiO}_{2}$ diffraction data remained same during heating and annealing 


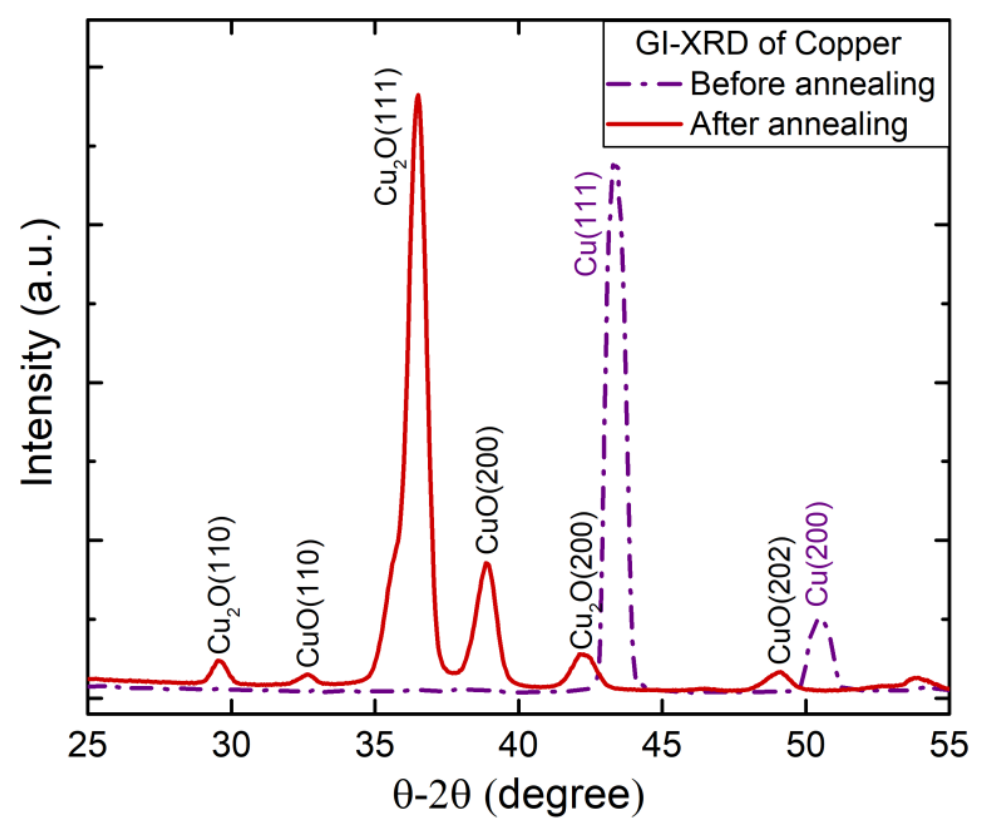

Figure S3. GI-XRD of bare copper before annealing and after annealing for 4 hours at $350^{\circ} \mathrm{C}$. The copper (111) and (200) peaks completely converted into a mixture of oxide phases. 

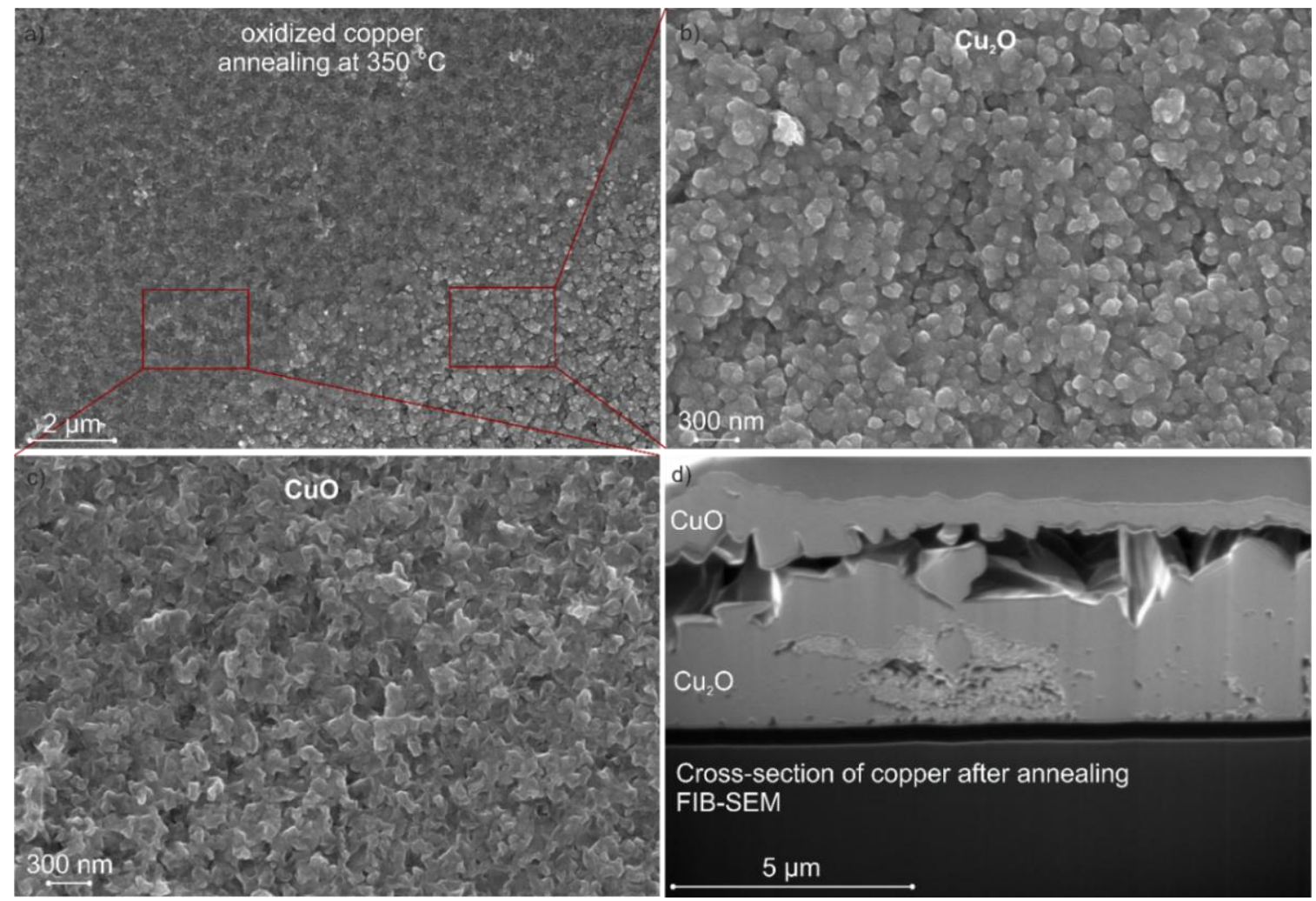

Figure S4. Surface properties of bare copper after 4 hours $350{ }^{\circ} \mathrm{C}$ annealing. a) Two different oxide phase of copper were observed in which part $b$ presents the inner part of sample with $\mathrm{Cu}_{2} \mathrm{O}$ oxide phase and part c presents the outer part of sample with $\mathrm{CuO}$ oxide phase. The crosssection of oxidized copper is presented in part $d$. The huge cavity between the oxide layers was attributed to the thermal stress relaxation during annealing and structural differences in which $\mathrm{Cu}_{2} \mathrm{O}$ shows cubic structure $(\alpha=4.27 \AA)$ and $\mathrm{CuO}$ has monoclinic structure $(a=0.468 \mathrm{~nm}$, $b=0.342 \mathrm{~nm}, c=0.512$ and $\left.\beta=99.54^{\circ}\right) .{ }^{1}$ The oxide phases were labeled according to Wan et al. observations in "corrosion behavior of copper at elevated temperature" study. ${ }^{1-2}$ 

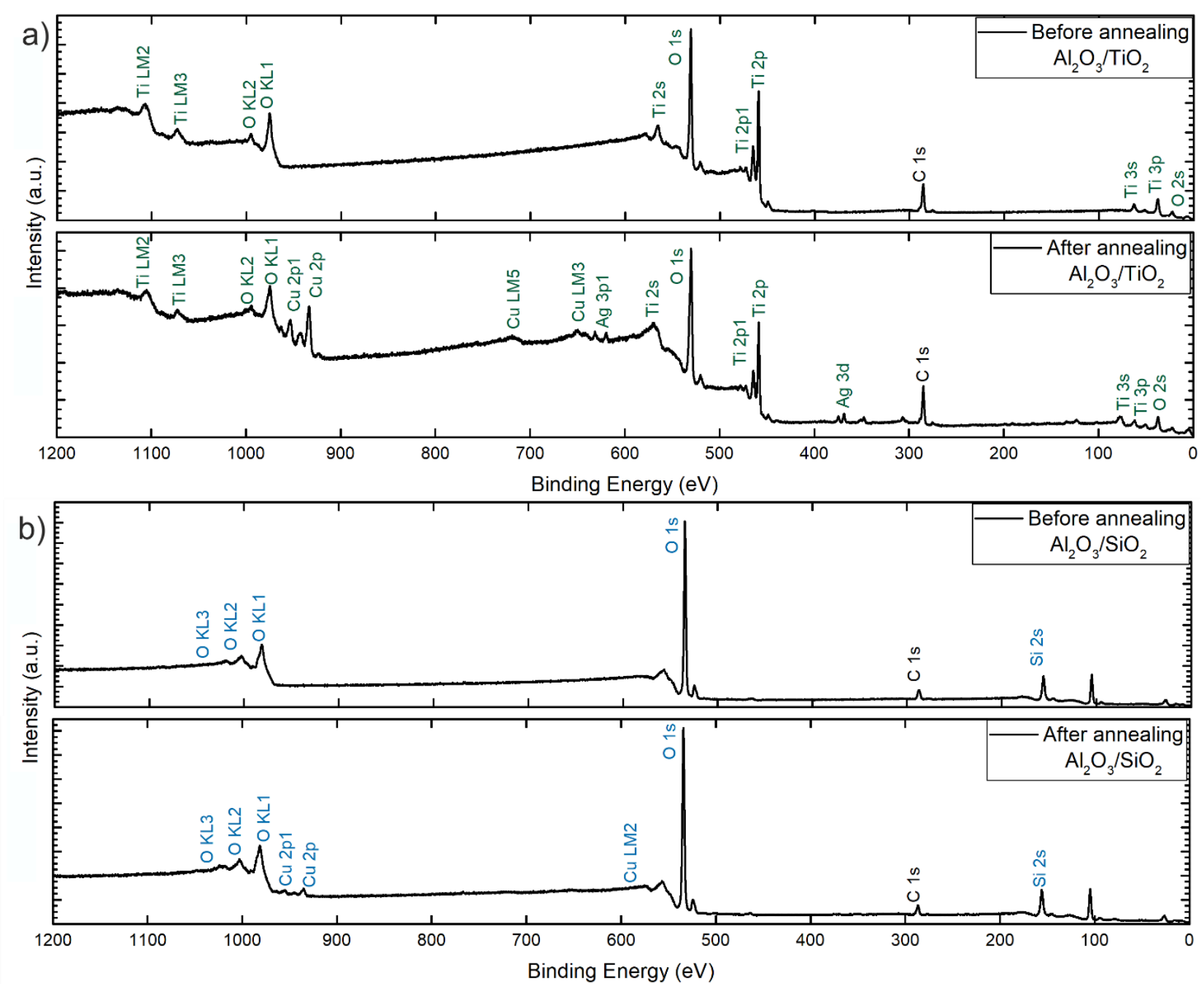

Figure S5. XPS survey spectra for before and after annealing a) $\mathrm{Al}_{2} \mathrm{O}_{3} / \mathrm{TiO}_{2}$ and $b$ ) $\mathrm{Al}_{2} \mathrm{O}_{3} / \mathrm{SiO}_{2}$ bilayers. The atomic percentage of copper for each annealed layer was estimated from the survey spectra over the $50 \mathrm{~mm}^{2}$ scanned area. The silver (Ag) was detected on $\mathrm{Al}_{2} \mathrm{O}_{3} / \mathrm{TiO}_{2}$ bilayers after annealing due to the using silver paste. According to curve fitting of annealed XPS spectra, the copper was found on both $\mathrm{Al}_{2} \mathrm{O}_{3} / \mathrm{TiO}_{2}$ and $\mathrm{Al}_{2} \mathrm{O}_{3} / \mathrm{SiO}_{2}$ bilayers with 5.2 at.\% and 0.7 at. $\%$, respectively. 
The energetic electrons penetrate a sample for some distance before they encounter and collide with a specimen atom. ${ }^{3-6}$ The penetration depth of electrons largely depends on the accelerating voltage, the material, and the density of the specimen. If the angle of the detector is constant, the penetration depth can be found by Equation $\mathrm{S} 1$ where $\rho$ is the density $\left(\mathrm{g} / \mathrm{cm}^{3}\right)$ and $E_{0}$ is the accelerating voltage $(\mathrm{keV}) .{ }^{7}$ Based on the assumption of $50 \mathrm{~nm}$ thick ALD layer, which consists only amorphous $\mathrm{SiO}_{2}$ with $2.2 \mathrm{~g} . \mathrm{cm}^{3}$ density $^{8}$, the penetration depth of electrons was calculated for $5 \mathrm{keV}, 2 \mathrm{keV}$, and $1 \mathrm{keV}$ given in Table $\mathrm{S} 1$.

Equation S1. The calculation of the penetration depth of electrons $(x)$

$$
x(\mu \mathrm{m})=\frac{0.1 E_{0}^{1.5}}{\rho}
$$

where $\rho$ is the density $\left(\mathrm{g} / \mathrm{cm}^{3}\right)$ and $E_{0}$ is the accelerating voltage $(\mathrm{keV})$

Table S1. The penetration depth in SEM according to accelerating voltage, calculated for $\mathrm{Al}_{2} \mathrm{O}_{3} / \mathrm{SiO}_{2}$ layer

\begin{tabular}{cc}
\hline $\begin{array}{c}\text { Accelerating Voltage } \\
(\mathbf{k e V})\end{array}$ & $\begin{array}{c}\text { Depth of Electron } \\
\text { Penetration }(\mathbf{n m})\end{array}$ \\
$\mathbf{1}$ & 46 \\
$\mathbf{2}$ & 129 \\
$\mathbf{5}$ & 510 \\
\hline
\end{tabular}



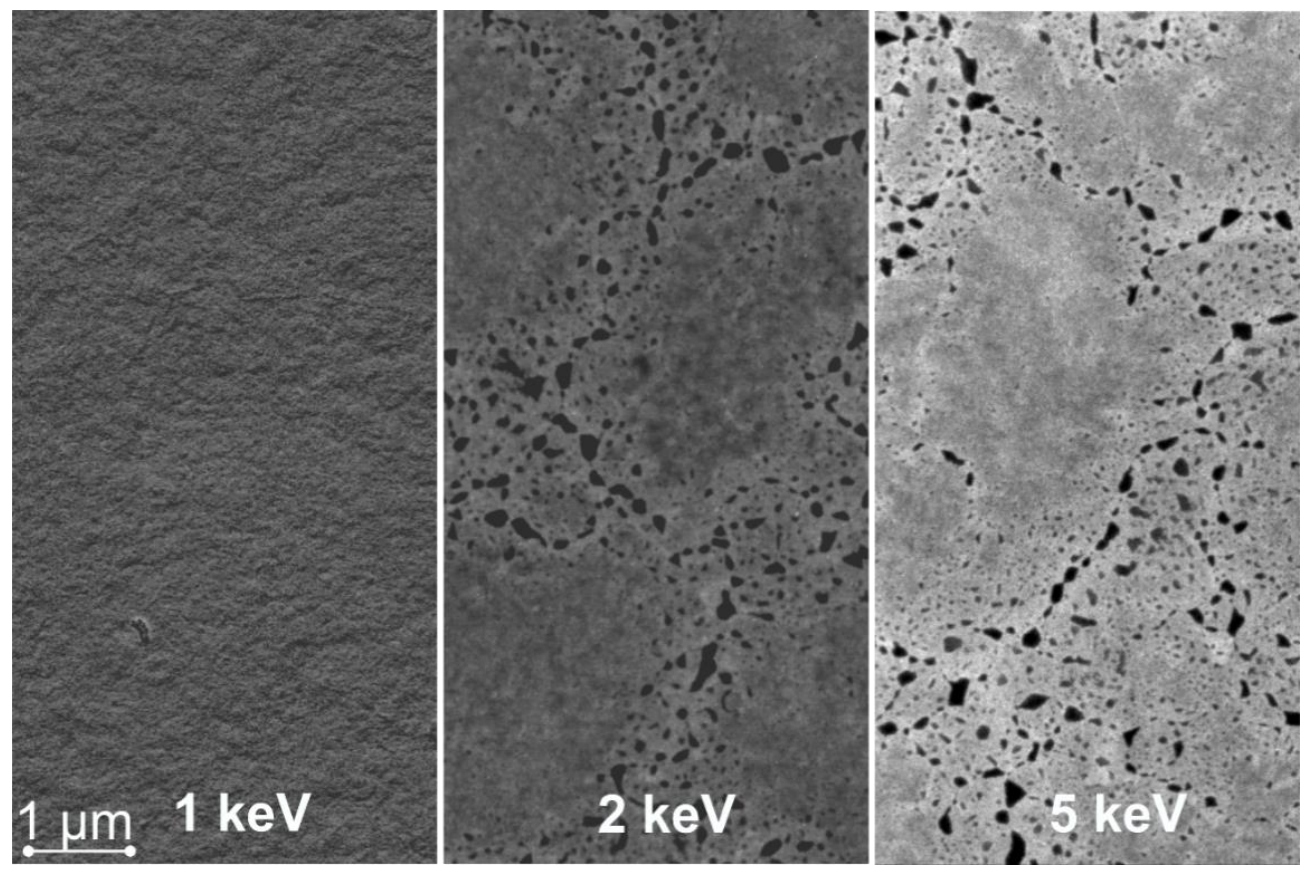

Figure S6. The penetration depth of electrons dependency on beam energy for the $\mathrm{Al}_{2} \mathrm{O}_{3} / \mathrm{SiO}_{2}$ bilayer after annealing. The SEM images were taken by InLens detector. While the low beam energy, $1 \mathrm{keV}$, did not showed the voids, they appeared by increasing the energy to $2 \mathrm{keV}$ and $5 \mathrm{keV}$. As the penetration depth was increased, it was possible to analyze subsurface that voids were observed. 

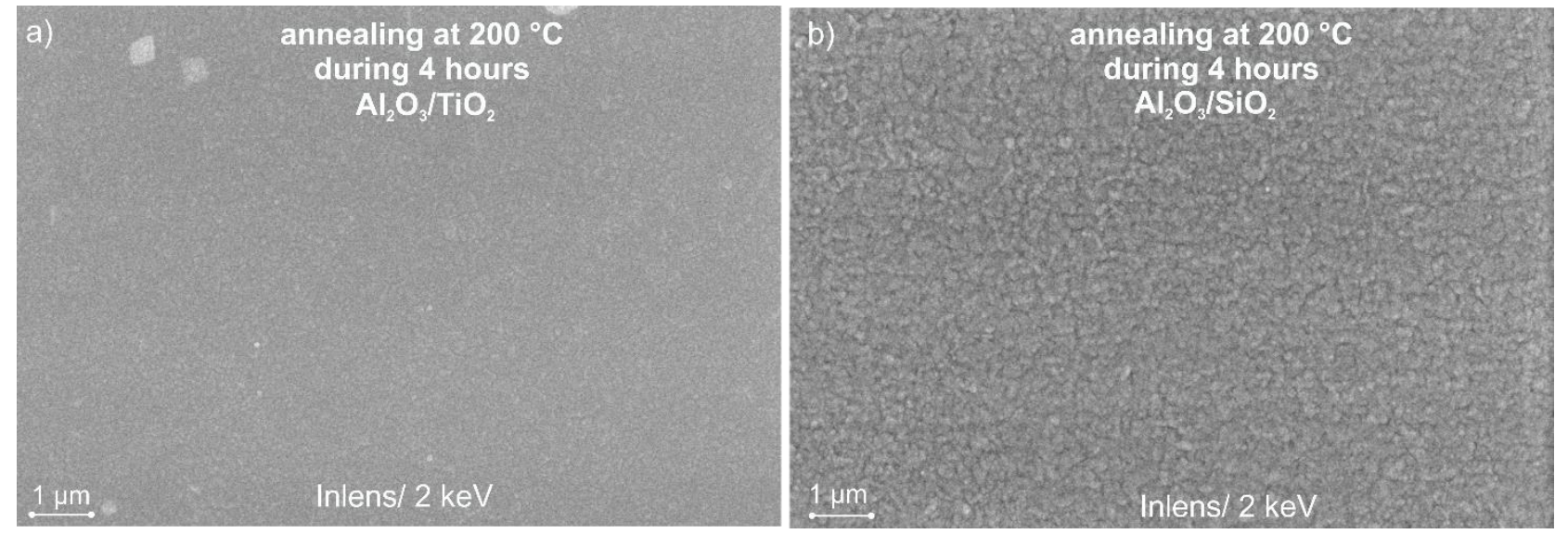

Figure S7. The effect of annealing on the morphology at $200{ }^{\circ} \mathrm{C}$ for 4 hours a) $\mathrm{Al}_{2} \mathrm{O}_{3} / \mathrm{TiO}_{2}$ b) $\mathrm{Al}_{2} \mathrm{O}_{3} / \mathrm{SiO}_{2}$. The ALD samples were annealed at $200{ }^{\circ} \mathrm{C}$ for 4 hours under atmospheric conditions as in the case of $350^{\circ} \mathrm{C}$. The SEM analysis revealed that the morphology remained same after annealing at $200{ }^{\circ} \mathrm{C}$ as copper was not observed on the surface and voids structure s were not formed on the subsurface. While annealing at $350^{\circ} \mathrm{C}$ leads to morphological changes, at lower temperatures such as $200^{\circ} \mathrm{C}$, the whole film stack in both $\mathrm{Al}_{2} \mathrm{O}_{3} / \mathrm{TiO}_{2}$ and $\mathrm{Al}_{2} \mathrm{O}_{3} / \mathrm{SiO}_{2}$ seems to be much more stable based on the SEM analysis. 

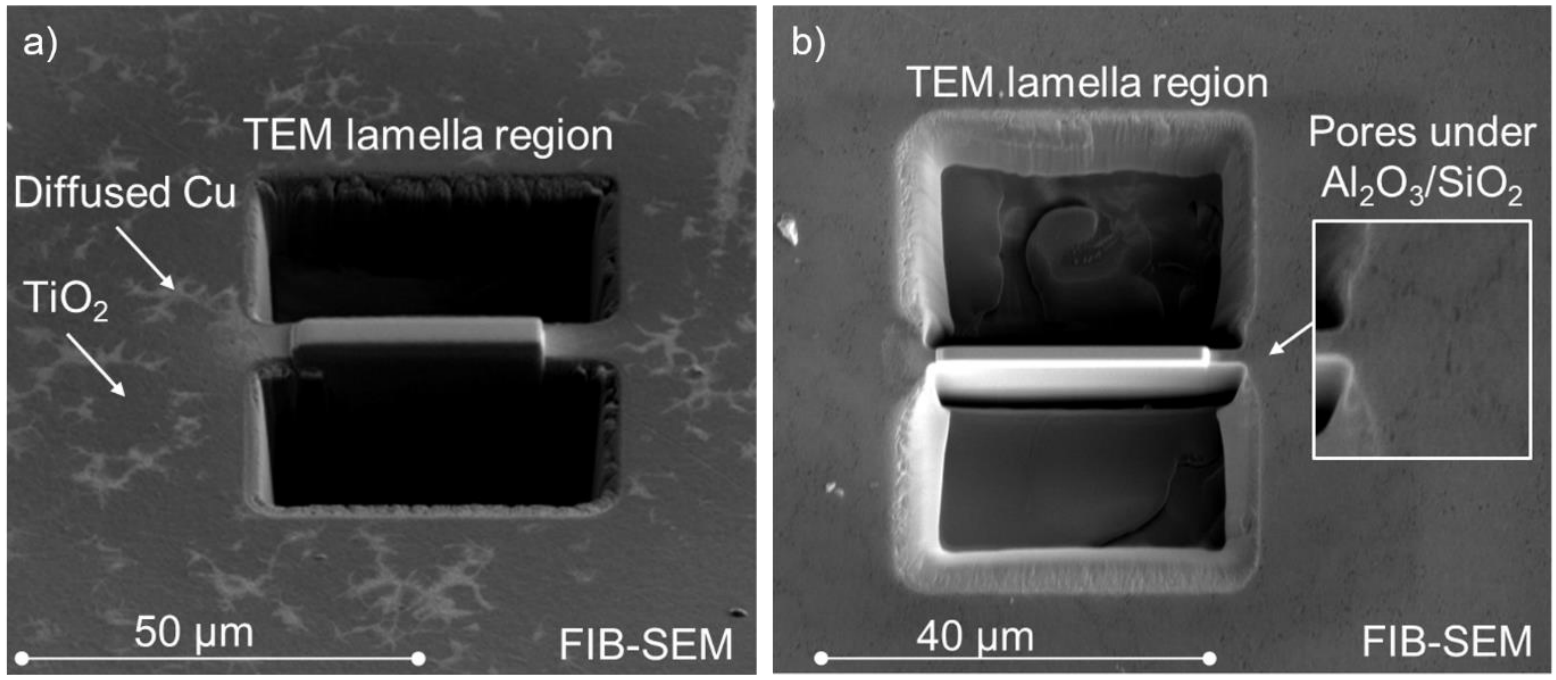

Figure S8. TEM lamella preparation for a) $\mathrm{Al}_{2} \mathrm{O}_{3} / \mathrm{TiO}_{2}$ b) $\mathrm{Al}_{2} \mathrm{O}_{3} / \mathrm{SiO}_{2}$ The FIB-cut were chosen from the specific regions which includes copper on the surface in $\mathrm{Al}_{2} \mathrm{O}_{3} / \mathrm{TiO}_{2}$ sample and voids in $\mathrm{Al}_{2} \mathrm{O}_{3} / \mathrm{SiO}_{2}$ sample 
Table S2. Effect of annealing on sheet resistance of copper and ALD bilayers

\begin{tabular}{cc}
\hline Sample & $\begin{array}{c}\text { Sheet Resistance } \\
(\mathrm{mohm} / \square)\end{array}$ \\
bare Copper & $14.89 \pm 0.24$ \\
post-annealed Copper & Contact limit-high resistance \\
as-deposited $\mathrm{Al}_{2} \mathrm{O}_{3} / \mathrm{TiO}_{2}$ on copper & $15.03 \pm 0.59$ \\
post-annealed $\mathrm{Al}_{2} \mathrm{O}_{3} / \mathrm{TiO}_{2}$ on copper & $15.55 \pm 0.45$ \\
as-deposited $\mathrm{Al}_{2} \mathrm{O}_{3} / \mathrm{SiO}_{2}$ on copper & $14.68 \pm 0.60$ \\
post-annealed $\mathrm{Al}_{2} \mathrm{O}_{3} / \mathrm{SiO}_{2}$ on copper & $15.14 \pm 0.29$ \\
\hline
\end{tabular}

The resistivity measurements were performed by using four point probe (FFP) by Jandel multiposition wafer probe 8 inch model with $1 \mathrm{~mm}$ probe spacing, $100 \mu \mathrm{m}$ tip radius and 100 g loading (max. current $100 \mathrm{~mA}$ and max voltage $100 \mathrm{mV}$ ). The correction factor, 4.53, were determined in infinite case according to substrate size and probe spacing. ${ }^{10}$ The average sheet resistance and standard deviations were calculated from 3 different sample which include forward and reverse bias on each sample. 


\section{REFERENCES}

1. Choudhary, S.; Sarma, J. V. N.; Pande, S.; Ababou-Girard, S.; Turban, P.; Lepine, B.; Gangopadhyay, S., Oxidation mechanism of thin Cu films: A gateway towards the formation of single oxide phase. AIP Advances 2018, 8 (5), 055114.

2. Wang, J.-P.; Cho, W., Oxidation Behavior of Pure Copper in Oxygen and/or Water Vapor at Intermediate Temperature. Isij International - ISIJ INT 2009, 49, 1926-1931.

3. Wang, S. B., et al., , VOx thin films obtained by ion beam sputtering and oxidation process. Surface and Coatings Technology 191, 191 (2-3), 330-334.

4. Quinn, G. D., R. Gettings, and L.K. Ives, A Standard Reference Material for Vickers Hardness of Ceramics and Hardmetals. 2004.

5. Fabrizio, e. D., et al.,, High-efficiency Multilevel Zone Plates for keV X-rays. Nature 1999, 401 (6756), 895-898.

6. Pinos, J.; Mikmekova, S.; Frank, L., About the Information Depth of Backscattered Electron Imaging. J Microsc 2017, 266 (3), 335-342.

7. Schneider, G., X-ray Microscope with Zone Plates, U. Patent, Editor. 2000, Bastian Nieman; Schneider., G. X-ray microscope with zone plates. 2000.

8. Ma, H. P.; Yang, J. H.; Yang, J. G.; Zhu, L. Y.; Huang, W.; Yuan, G. J.; Feng, J. J.; Jen, T. C.; Lu, H. L., Systematic Study of the SiOx Film with Different Stoichiometry by Plasma-Enhanced Atomic Layer Deposition and Its Application in $\mathrm{SiOx} / \mathrm{SiO}_{2}$ Super-Lattice. Nanomaterials (Basel) 2019, 9 (1).

9. Vanhaverbeke, C.; Cauwe, M.; Stockman, A.; Op de Beeck, M.; De Smet, H., Comparison of Copper Electroplating, Copper Wet Etching and Linear Sweep Voltammetry as Techniques to Investigate the Porosity of Atomic Layer Deposited $\mathrm{Al}_{2} \mathrm{O}_{3}$. Thin Solid Films 2019, 686, 137424.

10. Logan, M. A., Sheet Resistivity Measurements on Rectangular Surfaces: General Solution for Four Point Probe Conversion Factors. The Bell System Technical Journal 1967, 46 (10), 2277-2322. 